\title{
Butyrylcholinesterase deficiency identified by preoperative patient interview
}

\author{
Serin Lee, Jung Woo Han, and Eun Sung Kim \\ Department of Anesthesiology and Pain Medicine, Seoul St. Mary's Hospital, College of Medicine, The Catholic University of Korea, \\ Seoul, Korea
}

The preoperative evaluation of a patient for anesthesia increases the practitioner's awareness of the patient's medical condition and becomes the foundation for perioperative management plans. Furthermore, preoperative visits for interviews should also provide information about the anesthesia itself and instructions for the patient with respect to the perioperative period [1]. The following case report details the importance of a medical interview by describing a patient with undiscovered butyrylcholinesterase (BCHE) deficiency.

A 54-year-old female patient was admitted to hospital for a total thyroidectomy for papillary thyroid cancer. Her medical records showed essential hypertension and angina without recent symptoms. She was examined for preoperative evaluation; no specific findings were observed. The day before the surgery, the anesthesiologist met her for a medical interview and obtained new information about her past surgeries.

Twenty-five years previously, she underwent caesarean section. She could not recall the administered drugs, but she could not respire after the surgery. She required ventilator support for $13 \mathrm{~h}$. Ten years previously, she underwent a hemorrhoidectomy and had received $50 \mathrm{mg}$ of succinylcholine. After the surgery, she could not speak or move freely, and thus required observation for another $3 \mathrm{~h}$. We presumed that she had a problem with BCHE, so we decided to use atracurium for induction.

On the day of the surgery, anesthetic management included $2 \mathrm{mg}$ of midazolam for premedication. Her vital signs were within the normal range. A nerve stimulator assessing ulnar nerve activity and train-of-four (TOF) monitoring was initiated and revealed $98 \%$ activity. Induction drugs included $50 \mathrm{mg}$ of $1 \%$ lidocaine and $120 \mathrm{mg}$ of $1 \%$ propofol. Following airway confirmation, $10 \mathrm{mg}$ of atracurium was administered and TOF revealed $52 \%$ activity. She was given an additional $10 \mathrm{mg}$ of atracurium. Two minutes later, TOF revealed $4 \%$, and was intubated. During the surgery, anesthesia was maintained with air, oxygen, desflurane, and remifentanil. At the end of the surgery, the TOF revealed $72 \%$ activity, and she received $10 \mathrm{mg}$ of pyridostigmine bromide and $0.4 \mathrm{mg}$ of glycopyrrolate. Three minutes later, TOF revealed $98 \%$ and she could lift her head and grip her hands. She was extubated and transferred to the post-anesthetic care unit. The postoperative recovery period was uneventful, and she was discharged from the hospital without complications.

The plasma BCHE level on the day after surgery was $123 \mathrm{U} / \mathrm{L}$ (normal range, 5320-12920 U/L), measured with butyrylthiocholine iodide as a substrate by the Ellman reaction at $24^{\circ} \mathrm{C}$ in a spectrophotometer (UV2550; Shimadzu, Kyoto, Japan). We referred her to the Department of Clinical Pathology for further evaluation. Informed consent was obtained. Her genomic DNA was extracted from peripheral white cells, and direct sequencing for exon 2 including intron-exon boundaries was performed. Sequence analysis of the BCHE gene revealed a newly defined missense mutation (p.Phe71Leu) and previously reported 1-bp duplication frameshift (p.Asn134Lysfs*24) (Fig. 1). We suggested genetic evaluation of her family members, but they had died or were living outside the country. Thus, we proposed further evaluation.

In the clinical epidemiology of disease, three factors to be

Corresponding author: Eun Sung Kim, M.D., Ph.D., Department of Anesthesiology and Pain Medicine, Seoul St. Mary's Hospital, College of Medicine, The Catholic University of Korea, 505, Banpo-dong, Seocho-gu, 137-040, Korea. Tel: 82-2-2258-2236, Fax: 82-2-591-1592, E-mail: euns1503@catholic.ac.kr

() This is an open-access article distributed under the terms of the Creative Commons Attribution Non-Commercial License (http:// creativecommons.org/licenses/by-nc/3.0/), which permits unrestricted non-commercial use, distribution, and reproduction in any medium, provided the original work is properly cited. 

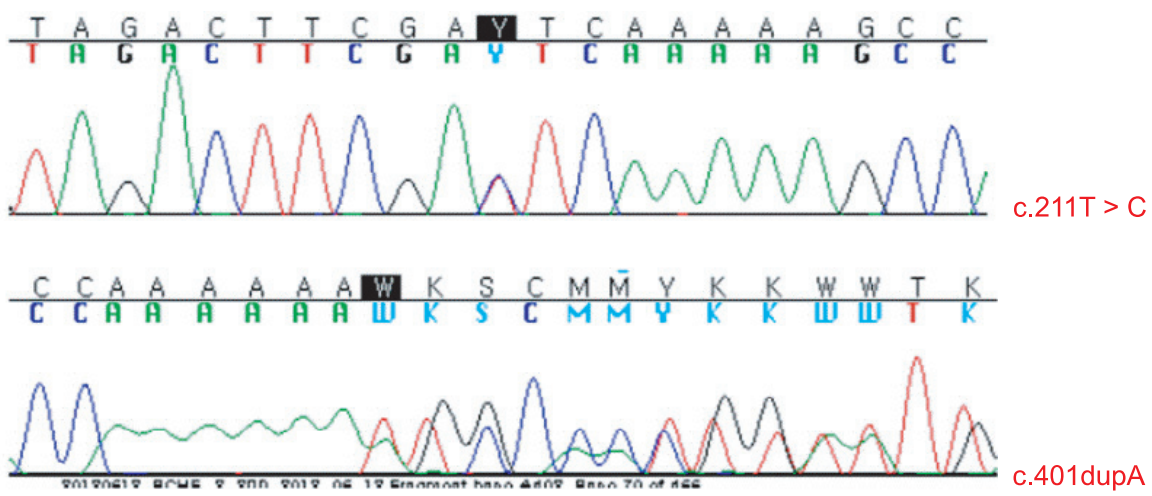

\begin{tabular}{|c|c|c|c|c|c|}
\hline Type & $\begin{array}{c}\text { Exon/ } \\
\text { intron \# }\end{array}$ & $\begin{array}{c}\text { Nucleotide } \\
\text { change }\end{array}$ & $\begin{array}{c}\text { Amino acid } \\
\text { change }\end{array}$ & Zygosity & rs ID \\
\hline $\begin{array}{c}\text { Mutation } \\
\text { predicted }\end{array}$ & Exon2 & c.211T > C & p.Phe 71Leu & Heterozygous & - \\
\hline Mutation & Exon2 & c.401dupA & $p . A s n 134$ Lysfs 24 & Heterozygous & - \\
\hline
\end{tabular}

Fig. 1. The analysis of the gene. The analyzed gene is butyrylcholinesterase on 3q26.1-q26.2. The method is direct sequencing for exon 2 including intronexon boundaries. Two mutation are verified: newly missen mutation of p.Phe71Leu, 1-bp duplication frameshift; the trigger of premaure termination codon (p.Asn134Lysfs*24). considered are occurrence, seriousness, and treatability. Although BCHE deficiency is very uncommon, it is a serious condition due to its difficulty to diagnose clinically and is potentially fatal. It is an important condition because it is treatable, when specialized postoperative management is provided. Patients with this deficiency have a marked sensitivity to suxamethonium and similar cholinesterase-inhibiting drugs, leading to prolonged postanesthesia apnea; death may follow administration of these drugs [2].

Genetically inherited BCHE deficiency is typically regarded as an autosomal recessive trait. BCHE deficiency is associated with the BCHE gene. Its variants may result in minimal to extreme postsuccinylcholine apnea and paralysis. The frequency of inheritance varies by population but, in general, heterozygotes account for 1 in 25 to 50 individuals, homozygotes account for 1 in 3000 individuals. Many non-genetic factors have been described as acquired conditions affecting BCHE activity, including advanced age, liver disease, renal disease, malnutrition, pregnancy, malignancy, burns, cardiopulmonary bypass, and leprosy. Some medications also affect activity, such as oral contraceptives, monoamine oxidase inhibitors, aspirin, and metoclopramide [3].

Atracurium is a non-depolarizing neuromuscular blocking agent. The presence of two-carbon separations between quaternary nitrogen and ester carbonyl provides the basis for a Hofmann elimination reaction. Furthermore, it can undergo ester hydrolysis. Therefore, atracurium is largely free of BCHE deficiency and can be safely used in BCHE-deficient patients.

In the present case, the patient had no non-genetic factors. Therefore, we believe that she had a genetic problem and analyzed her DNA. Likewise, we decided to use atracurium for intu- bation, and she successfully recovered from paralysis at the end of surgery.

The limitation of the present case is that we could not use cisatracurium for induction. Cisatracurium is the isomer of atracurium and metabolized according to Hofmann elimination. Therefore, in this case, cisatracurium was a more suitable drug for induction and maintenance of anesthesia. However, the use of cisatracurium is restrictive because, in our country, it is not a popular drug. Nevertheless, several studies have shown the safety of atracurium in BCHE deficient patients. Merrett et al. [4] demonstrated the major pathway of atracurium in vitro. There was no difference in the rate of degradation of atracurium in normal plasma versus plasma with low plasma cholinesterase activity. Kim et al. [5] measured BCHE levels during surgery. They administered pancurium, vecuronium, and atracurium. After administration of the drugs, the BCHE level and duration of paralysis were checked. The group administered atracurium displayed higher BCHE levels than the other groups. The cause was assumed to be the difference in ester structure that existed due to abnormal serum cholinesterase. Thus, the use of atracurium in BCHE-deficient patients is an appropriate anesthetic management.

According to previous studies, most cases of BCHE deficiency involve incidentally prolonged paralysis after surgery. Consequently, patients suffered from unexpected, delayed extubation and unnecessary care in the intensive care unit. The present case is meaningful because it shows that anesthetic complications can be avoided by preoperative interview and contributes to education of the patient regarding overcoming the fear of general anesthesia. 


\section{References}

1. Harms C, Kindler CH. The preoperative anaesthetic visit. Ther Umsch 2009; 66: 503-8.

2. Kim JH. Preoperative evaluation of a surgical patient; preanesthetic interview by anesthesiology residents. Korean J Anesthesiol 2012; 62: 207-8.

3. Soliday FK, Conley YP, Henker R. Pseudocholinesterase deficiency: a comprehensive review of genetic, acquired, and drug influences. AANA J 2010; 78: 313-20.

4. Merrett RA, Thompson CW, Webb FW. In vitro degradation of atracurium in human plasma. Br J Anaesth 1983; 55: 61-6.

5. Kim SY, Lee JS, Yoo JS, Hwang KH, Kim SC, Park W, et al. Infuence of various muscle relaxants on the plasma cholinesterase activity. Korean J Anesthesiol 1998; 34: 770-9. 